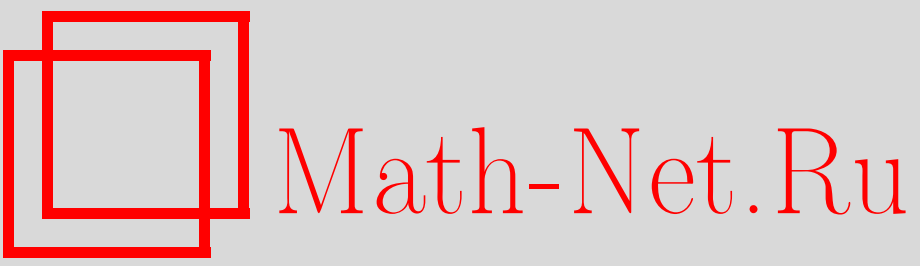

В. М. Бабич, А. М. Вершик, В. С. Виденский, О. Л. Виноградов, И. К. Даугавет, Н. Ю. Додонов, В. В. Жук, Б. М. Макаров, А. Н. Подкорытов, Ю. Г. Решетняк, М. А. Скопина, В. Л. Файншмидт, В. П. Хавин, Н. А. Широков, Гаральд Исидорович Натансон (некролог), УМН, 2004, том 59, выпуск 4, 181-185

DOI: https://doi.org/10.4213/rm761

Использование Общероссийского математического портала Math-Net.Ru подразумевает, что вы прочитали и согласны с пользовательским соглашением http://www.mathnet.ru/rus/agreement

Параметры загрузки:

IP: 54.92 .164 .108

26 апреля 2023 г., 16:39:48 


\section{ГАРАЛЬД ИСИДОРОВИЧ НАТАНСОН}

24 июля 2003 г. в Санкт-Петербурге на 74-м году жизни скончался известный математик Гаральд Исидорович Натансон. Он родился в Ленинграде 9 мая 1930 г. в семье вьпускников математико-механического факултета Ленинградского государственного университета. Его отецИсидор Павлович Натансон - замечательный педагог, крупньй специалист по вещественному анализу и теории приближений, автор широко известных книг "Теория функций вешественной переменной" и "Конструктивная теория функций”. Мать - Елизавета Петровна Натансон (урожденная Соколова) - статистик-демографф, кандидат наук. Родители уделяли много внимания воспитанию сына и, в частности, активно содействовали развитию его математических способностей, проявившихся довольно рано. В 1938 г. Г.И. Натансон поступил сразу во 2-й класс школы в Ленинграде. В 1941 г. семья была эвакуирована в город Барнаул, откуда возвратилась в 1944 г.

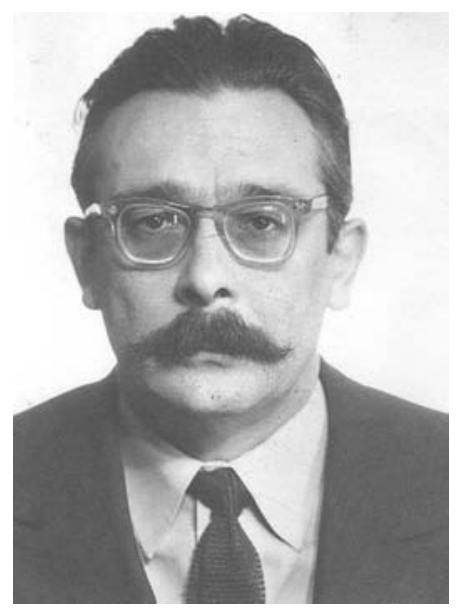

Гаральд Исидорович поступил в 8-й класс школы № 155 . Учась в 9-м классе, он начал заниматься в математическом кружке Ленинградского Дворца пионеров, руководимом прекрасным педагогом и математиком В.А. Залгаллером. Через год стал одним из победителей Ленинградской городской математической олимпиады школьников-вьпускников.

Окончив в 1947 г. школу, Гаральд Исидорович поступил на математико-механический факультет ЛГУ. Он был одним из лучших студентов курса и в 1952 г. получил диплом с отличием. Во время учебы, наряду с обязательными дисциплинами, он прослушал много факультативных курсов и участвовал в нескольких семинарах, относящихся к различным разделам математики и механики, в частности, посещал лекции И. П. Гинзбурга по механике сплошной среды, С. М. Лозинского по вьчислительной математике, Л. В. Канторовича по функциональному анализу, И. П. Натансона по конструктивной теории функций.

Уже в студенческие годы проявилось богатство интересов Г.И. Натансона. Несмотря на плохое зрение, он имел разряд по борьбе самбо, прекрасно ездил на велосипеде, был капитаном шахматно-шашечной команды математико-механического факултета. В летние каникулы неоднократно в составе студенческих стройотрядов работал землекопом на строительстве сельских ГЭС.

После окончания математико-механического факултета ЛГу он был принят в аспирантуру кафедры математического анализа Ленинградского педагогического института им. А. И. Герцена, а затем проработал на этой кафедре до 1966 г., причем в последние годы был ее заведующим. В 1957 г. он защитил кандидатскую диссертацию. В 1960 г. Г. И. Натансон организовал в пединституте научньй семинар по конструктивной теории функций, которьй впоследствии перерос в общегородской, работающий и поныне. Как правило, все диссертации по конструктивной теории функций, защищавшиеся в Ленинграде, а также те, на которые ленинградские математики давали отзывы, вначале обсуждались на этом семинаре. Имея большие познания в различных 
областях математики и обладая редкой способностью быстро вникать в содержание новых для него работ, Г.И. Натансон был идеальным руководителем семинара.

В 1966 г. Г. И. Натансон перешел на кафедру математического анализа Ленинградского университета, где и работал до конца жизни. В 1968 г. он защитил докторскую диссертацию. Будучи профессором кафедры, Гаральд Исидорович читал лекции по общему курсу математического анализа, вел спецкурсы и спецсеминары по различным разделам теории функций. Гаральд Исидорович был прекрасным преподавателем, и его занятия неизменно пользовались большой популярностью у многих поколений студентов. Под его руководством было написано болшшое число дипломных работ. Пятнадщать его учеников стали кандидатами наук, двое позже защитили докторские диссертации.

$\mathrm{C}$ начала работы Ленинградского математического общества на протяжении более 20 лет Г. И. Натансон - член его правления. Он был доброжелательным человеком, и потому к нему нередко обращались с математическими вопросами как студенты, так и сложившиеся специалисты в различных областях науки. С 1974 по 2002 г. Г. И. Натансон возглавлял жюри городской математической олимпиады для студентов ВТУЗ'ов.

О том, каким человеком был Г.И. Натансон, о его демократизме, отзывчивости, исключительной памяти, разносторонности его интересов, чувстве юмора можно говорить много. Но невозможно не сказать еще об одной стороне его личности, возможно важнейшей. Это - внутреннее достоинство и порядочность. "Делай, что должно, и пусть люди говорят, что угодно". Этот старинньй девиз очень точно отражает качества характера Гаралшда Исидоровича. То, что он считал необходимым, он делал, обращая удивительно мало внимания на возможные неблагоприятные последствия для него лично.

В первых работах Г. И. Натансона исследуется применение метода суммирования Бернштейна-Рогозинского к рядам Фурье-Якоби, интерполяционным процессам с узлами в корнях многочленов Якоби, к суммированию рядов Фурье по собственным функциям задачи Штурма-Лиувилля. Ряд его работ посвящен приближению функций линейньми комбинациями собственных функций краевой задачи Штурма-Лиувилля. В частности, он дал уточнение прямых теорем аппроксимации типа Джексона и нашел аналоги обратных теорем теории периодических функций в той форме, как они незадолго до этого были установлены С. М. Лозинским, рассмотрел аналог интерполяционного многочлена Лагранжа, приспособленный к задаче Штурма-Лиувилля. Эти работы составили основу кандидатской диссертации Г. И. Натансона "О некоторых применениях асимптотических формул в конструктивной теории функций”, защищенной им в 1957 г. при оппонентах С. М. Лозинском и М. К. Гавурине. В диссертации дано новое доказательство неравенства Е. Карлсон для линейных комбинаций функций Штурма-Лиувилля (аналога известного неравенства С.Н. Бернштейна для производной тригонометрического полинома). Это доказательство при менее ограничительных предположениях занимает чуть более одной страницы против 10 страниц доказательства Е. Карлсон. Диссертация получила высокие отзывы.

Научные результаты Г. И. Натансона следующего десятилетия составили его докторскую диссертацию "Приближение функций некоторыми линейными полиномиальными операторами", защищенную им в июне 1968 г. на Ученом совете математико-механического факултета Ленинградского государственного университета. Оппонентами были В. С. Виденский, В. К. Дзядьк, С.М. Лозинский.

Работа посвящена одной из основных задач конструктивной теории функций - исследованию свойств аппроксимационных процессов. В ней рассматриваются приближения в равномерной метрике линейными полиномиальными операторами. Исследуются такие приближающие процессы: сумматорные формулы, полученные применением метода множителей к интерполяционному процессу Лагранжа с узлами в корнях многочленов Якоби; мультипликаторы, действующие на тригонометрические ряды Фурье; частичные суммы ряда Фурье по многочленам Эрмита; интерполяционный процесс Лагранжа с узлами в корнях многочленов Якоби; частичные суммы рядов Фурье по многочленам Якоби; частичные суммы тригонометрического ряда Фурье. Кроме того, отдельная глава посвящена так назьваемой проблеме насьщения.

В значительной части перечисленных случаев целью исследования являлось нахождение асимптотической формулы для величины $\sup _{f \in G}\left|U_{n}(f, x)-f(x)\right|$, где $G$ - определенный класс функций, а $U_{n}$ - изучаемьй оператор. Г.И. Натансону удалось получить асимптотическое 
выражение для указанного отклонения, когда в качестве $U_{n}$ фогуррируют частичные суммы рядов Фурье по многочленам Эрмита и многочленам Якоби.

Автором получены (и это существенное достижение) окончательные по порядку двусторонние оценки функций Лебега для двух классических процессов - интерполяционного процесса с узлами Якоби и сумм Фурье-Якоби.

Явлению Гиббса при различных конкретных методах суммирования рядов Фурье посвящено много работ. Г. И. Натансон дает легко проверяемые достаточные условия наличия явления Гиббса, приложимые к широкому классу методов.

В теории тригонометрических рядов Фурье автором выделены естественные классы функций, для которых суммы Фурье дают приближение порядка наилучшего.

Работы Г.И. Натансона после защиты докторской диссертации можно разбить на три большие группы: приближение алгебраическими многочленами, тригонометрическими многочленами и сплайнами. В этот период им получено очень много интересных результатов. Мы отметим только три из них, руководствуясь простотой формулировок.

В [67] найдена точная постоянная в оценке Беренса-Лоренца равномерного приближения функции класса $C 2([0,1])$ многочленами Бернштейна.

В [50] получена (с точной константой) новая оценка для погрешности классической квадратурной формулы Ньютона-Котеса с $m+1$ узлами $(m-$ четное) через модуль непрерывности порядка $m$ второй производной рассматриваемой функции.

Несколько раньше, в [46], было найдено полезное и простое выражение для уклонения $m$-го многочлена Лагранжа по равноотстоящим узлам от интерполируемой фуункии через $m$-ю разность ее производной.

Богатый педагогический опыт Г. И. Натансона нашел отражение в написанной им в соавторстве с В. В. Жуком книге "Тригонометрические ряды Фурье и элементы теории аппроксимации". Она существенно отличается от аналогичных пособий тем, что в ней ряды Фурье излагаются с позиций современной теории приближений. Это позволило, с одной стороны, включить (в рамках ограниченного объема) много материала, ранее не освещавшегося в литературе такого рода, а с другой - сделать более ясной идейную сторону рассматриваемых вопросов. Тщательньй отбор материала и болшшое внимание, уделенное методическим моментам, позволили провести изложение в форме, доступной студентам младших курсов математических специалнностей вузов и инженерам. Часть материала, включенного в книгу, является новой и с научной точки зрения.

Г. И. Натансон является одним из авторов книги “Линейные уравнения математической физики" из серии "Справочная математическая библиотека", переведенной на ряд иностранных языков. Он также принимал участие в создании книги "Математика и механика в изданиях Академии наук СССР. Библиография" (это трехтомное издание осуществлялось под общей редакцией В.И. Смирнова).

Мы навсегда сохраним светлую память о прекрасном математике, замечательном преподавателе и воспитателе научной смены, добром и интересном человеке Гаральде Исидоровиче Натансоне.

В.М. Бабич, А.М. Вершик, В.С. Виденский, О. Л. Виноградов, И. К. Даугавет, Н. Ю. Додонов, В. В. Жук, Б. М. Макаров, А.Н. Подкорытов, Ю.Г. Решетняк, М. А. Скопина, В. Л. Файнимидт, В. П. Хавин, Н. А. Широков

\section{СПИСОК ТРУДОВ Г.И. НАТАНСОНА}

[22] Математика и механика в изданиях Академии наук СССР: Библиографияя / Под ред. В.И. Смирнова. Т. 3. М.-Л.: Изд-во АН СССР, 1957 (совм. с В.Б. Португалем и В. П. Алексеевой)

[23] Рецензия на книгу: Л. М. Грейвз. Теория функций вещественных переменных // Новые книги за рубежом. Сер. А. 1957. № 6. С. 18-21

Начало списка см. в сборниках: Математика в СССР за сорок лет, 1917-1957. Т. II. М.: Физматгиз, 1959. С. 497-498; Математика в СССР, 1958-1967. М.: Наука, 1969. С. 954-955. 
[24] Николай Александрович Сапогов (к 50-летию со дня рождения) // УМН. 1966. Т. 21. № 2. С. 259-260 (совм. с Ю. В. Линником, С. М. Лозинским, В. В. Петровым)

[25] Функция Лебега сумм Фурье-Якоби // Вестн. Ленингр. ун-та. Сер. матем., мех., астр. 1968. № 1. С. 11-23 (совм. с С. А. Агахановым)

[26] Отклонение сумм Фурье-Якоби в граничных точках промежутка ортогональности // Вестн. Ленингр. ун-та. Сер. матем., мех., астр. 1968. № 7. С. 15-27 (совм. с С. А. Агахановым)

[27] Приближение разрывных функций суммами Фурье // Докл. АН СССР. 1968. Т. 180. № 5. С. $1033-1036$

[28] Некоторые случаи, когда суммы Фурье дают приближение порядка наилучшего // Докл. AH CCCP. 1968. T. 183. № 6. С. 1254-1257

[29] Письмо в редакцию // Изв. вузов. Матем. 1969. №1 1(80). С. 109-110 (совм. с С. А. Агахановьмм

[30] К обратной задаче теории насыщения // Матем. заметки. 1969. Т. 6. № 5. С. 583-590 (совм. с В.В. Жуком)

[31] Некоторые замечания о корнях ултрасферических многочленов // Журн. вычисл. матем. и матем. физики. 1970. Т. 10. № 1. С. 183-187 (совм. с В. Б. Глаговским)

[32] О рядах Фурье непрерывных функций ограниченной вариации // Вестн. Ленингр. ун-та. Сер. матем., мех., астр. 1972. № 7. С. 154-155

[33] Свойства функций и рост производных приближающих полиномов // Докл. АН СССР. 1973. Т. 212. № 1. С. 12-19 (совм. с В. В. Жуком)

[34] Сергей Михайлович Лозинский (к 60-летию со дня рождения) // УМН. 1975. Т. 30. № 2. С. 229-234 (совм. с Б. З. Вулихом, И. П. Мысовских)

[35] О точности приближения периодических функций линейными методами // Вестн. Ленингр. ун-та. Сер. матем., мех., астр. 1975. № 13. С. 19-24 (совм. с В.В. Жуком)

[36] Об одном сумматорном процессе приближения // Вестн. Ленингр. ун-та. Сер. матем., мех., астр. 1977. № 1. С. 42-48 (совм. с В.В. Жуком)

[37] $\mathrm{K}$ вопросу приближения функций посредством положительных операторов // Ученые записки Тартуского ун-та. 1977. Т. 430. С. 58-69 (совм. с В. В. Жуком)

[38] О приближении дифференцируемых периодических функций линейными методами // Вестн. Ленингр. ун-та. Сер. матем., мех., астр. 1977. № 19. С. 16-21 (совм. с В. В. Жууком)

[39] О приближении непрерывных функций суммами Валле-Пуссена // Редколлегия журнала "Вестн. Ленингр. ун-та. Сер. матем., мех., астр.". Л. 1978; Рукопись деп. в ВИНИТИ 21 декабря 1978 г., № 3875-78 ДЕП. РЖКМат, 1979, 4Б126 (совм. с В. В. Жуком)

[40] К вопросу приближения в интегральной метрике функций, заданных на отрезке // Вестн. Ленингр. ун-та. Сер. матем., мех., астр. 1979. №13. С. 16-26 (совм. с В. В. Жуком)

[41] Средние геометрические последовательности наилучших приближений // Вестн. Ленингр. ун-та. Сер. матем., мех., астр. 1979. № 19. С. 50-52 (совм. с М. Ф. Тиманом)

[42] О константах в прямых теоремах теории приближения // Вестн. Ленингр. ун-та. Сер. матем., мех., астр. 1980. № 7. С. 5-9 (совм. с В.В. Жуком)

[43] Обратные теоремы конструктивной теории функций для периодических эквидистантных сплайнов // Вестн. Ленингр. ун-та. Сер. матем., мех., астр. 1983. № 7. С. 11-16 (совм. с В.В. Жуком)

[44] Тригонометрические ряды Фурье и элементы теории аппроксимации (учебное пособие). Л.: Изд-во ЛГУ, 1983 (совм. с В. В. Жуком)

[45] О применении способа И. П. Натансона и И. Ю. Харрик в алгебраическом случае // Теория операторов и теория функций. Л.: Изд-во ЛГУ, 1983. С. 166-170

[46] K теории кубических периодических сплайнов по равноотстоящим узлам // Вестн. Ленингр. ун-та. Сер. матем., мех., астр. 1984. № 1. С. 5-11 (совм. с В. В. Жуком)

[47] О втором модуленепрерывности // Исследования по теории функций многих вещественных переменных. Ярославль: Изд-во Ярославского гос. ун-та, 1984. С. 76-82

[48] Некоторые замечания о периодических эквидистантных сплайнах // Вестн. Ленингр. ун-та. Сер. матем., мех., астр. 1985. № 8. С. 12-17 (совм. с В. В. Жуком)

[49] Метод секущих // Наука и жизнь. 1985. № 6. С. 41-42 
[50] Замечание о формуле Ньютона-Котеса // Методы вычислений. Кубатурные формулы и функциональные уравнения. № 14. Л.: Изд-во ЛГУ, 1985. С. 58-59

[51] У Уочнение одного неравенства С.Н. Бернштейна // Геометрические вопросы теории функций и множеств. Калинин: Изд-во Калининского гос. ун-та, 1985. С. 121-125

[52] Об оценке констант Лебега сумм Валле-Пуссена // Геометрические вопросы теории функций и множеств. Калинин: Изд-во Калининского гос. ун-та, 1986. С. 102-107

[53-57] Методические рекомендации по использованию микрокалькулятора "Электроника Б3-34” в учебном процессе средних профттехучилищ. Ч. I-V. М.: Центральный институт усовершенствования учителей, 1989 (совм. с С.Н. Поздняковым, В.М. Рябовым и И.С. Храбрым)

[58] Методические указания к курсу “Аппроксимация функций”. Ч. 4. СПб: Изд-во СПбГУ 1991 (совм. с В. В. Жуком)

[59] Об одном неравенстве в теории сильнй аппроксимации // Вестн. Ленингр. ун-та. Сер. матем., мех., астр. 1992. № 3. С. 86-89 (совм. с Т. П. Дубовой)

[60] О приближении функций на стандартных симплексах // Докл. РАН. 1992. Т. 324. № 4. С. $734-737$ (совм. с В. В. Жуком)

[61] Об одной точной постоянной в теории многочленов Бернштейна // Тезисы докладов конференции, посвященной 70-летию проф. В. С. Виденского. СПб: Изд-во СПбГУ, 1992. C. $46-47$

[62] О приближении функций, заданных на отрезке // Методы вычислений. 1995. № 17. С. $105-121$ (совм. с В.В. Жуком)

[63] К 90-летию со дня рождения Геннадия Михайловича Голузина (1906-1952) // Вестн. С.-Петерб. ун-та. Сер. 1. 1996. № 3. С. 124-126 (совм. с С. А. Виноградовым, М. Г. Голузиной, Г. В. Кузьминой, В. П. Хавиным, Н. А. Широковым)

[64] К 90-летию со дня рождения Исидора Павловича Натансона (1906-1964) // Вестн. С.-Петерб. ун-та. Сер. 1. 1996. № 3. С. 127-130 (совм. с С. А. Виноградовым, В. В. Жуком, Б. М. Макаровым, В. П. Хавиным)

[65] О нормах сумм Фейера-Лежандра // Вестн. С.-Петерб. ун-та. Сер. 1. 1996. № 4. С. 25-34

[66] О приближении функций на стандартных симплексах // Труды С.-Петерб. матем. общества. 1996. Т. 4. С. 193-221 (совм. с В.В. Жуком)

[67] Об одной точной постоянной в теории полиномов Бернштейна // Вестн. С.-Петерб. ун-та. Cep. 1. 1998. № 3. C. 50-54

[68] С.Н. Бернштейн и конструктивная теория функций // Труды С.-Петерб. матем. общ-ва. 2000. T. 8. С. 70-95 (совм. с В. В. Жуком)

[69] Об одной теореме С. П. Гейсберга // Методы вычислений. 2001. № 19. С. 162-165

[70] Неравенства для модулей непрерывности в абстрактных банаховых пространствах // Проблемы математического анализа. 2001. № 23. С. 14-29 (совм. с В. В. Жуком)

[71] Полунормы и модули непрерывности функций, заданных на отрезке // Зап. науч. сем. ПОМИ. 2001. Т. 276. С. 155-203 (совм. с В. В. Жуком)

[72] О некоторых операторных соотношениях типа неравенств Маршо для модулей непрерывности // Вопросы современной теории аппроксимации. СПб: Изд-во СПбГУ (в печати) (совм. с В. В. Жуком) 